\title{
On methodology problems of developing innovative technologies taking into account anti-erosion measures
}

\author{
Yurii Sukhanovskii ${ }^{1,}$, , Anastasya Prushchik $^{1}$, Vladimir Vitovtov $^{1}$, and Alexandr Titov ${ }^{1}$ \\ ${ }^{1}$ FSBSI "Federal Agricultural Kursk Research Center"70b, Karl Marx St., Kursk, 305021, Russia
}

\begin{abstract}
The increase in world population and the decline in soil resources requires the increase in crop yields. Erosion and soil pollution are among the major threats to soil resources. With modern land use the rate of erosion exceeds the rate of soil formation. It is almost impossible to restore erosion soil loss. Soil pollution is a source of contaminated crop products and environment. In crop production innovative technologies are needed that must simultaneously solve three problems. The first problem is to ensure the necessary quantity and quality of crop products. The second problem is to preserve soil resources. The third one is to preserve the environment. In Russia, the increase in yields is mainly due to an increase in rates of mineral fertilizers, the use of plant protection tools and the use of varieties with a greater ability to utilize mineral fertilizers. In some regions of Russia, up to $70 \%$ of the arable land area is subject to water erosion of the soil. For the conditions of Russia, an analysis of the existing problems in assessing the long-term consequences of new technologies in crop production was carried out. Approaches have been proposed to solve some of the problems.
\end{abstract}

Keywords: technology development, methodology problems, consequence assessment, methods.

\section{Introduction.}

The need to increase crop yields is associated with an increase in the world population and with a decrease in soil resources (with a decrease in their quantity and with a deterioration in their quality). Soil erosion is classified as major threat to soil resources [1]. In the modern production of crop products soil resources subject to erosion humans use as non-reproducible resources (the rate of erosion is greater than the rate of soil formation). Global soil pollution occurs [2]. As a result, pollutants enter crop production and the environment (in the air and in water bodies). All this led to a global problem: how to continue to use the remaining soil resources? Innovative technologies are required to simultaneously solve the following problems: (1) the production of the required quantity and quality of crop products, (2) the conservation of soil resources, and (3) the preservation of the environment. To solve these problems, field tests of new technologies are being conducted, and methods are being developed to assess the long-term effects of their use. The development (testing inclusive) of technologies is carried out under specific soil and climatic conditions on which the effects depend. In Russia, the soil is prone to rain erosion, snowmelt erosion and wind erosion. In some regions, eroded soils on arable land reach $70 \%$ [3]. In Russia, the increase in yields is largely due to the use of increasing rates of mineral fertilizers, plant protection aids and the creation of varieties with a greater ability to utilize mineral fertilizers. Field experiments are mainly focused on yields.
The research purpose is to analyze problems in assessing the long-term consequences of innovative technologies for the conditions of Russia and proposals for their solution.

\section{Methodology and discussion.}

\subsection{The problem of assessing the dynamics of soil resources.}

There is a problem in estimating these resources using measured values. The amount of soil can be estimated by the arable land area $(A)$ and the thickness of the humus layer $(D)$. Their product determines the volume of soil $V$ $=A \cdot D$, i.e. the amount of soil. The integrated mathematical model [4] describes the dynamics of three processes: soil erosion, soil formation and transformation of organic matter entering the soil. Using the model, the following was established for the chernozems of Kursk Region: 200 years after virgin soil plowing, the error in calculating erosion soil losses is $13 \%$, and the error in calculating humus reserves in the soil layer $0-50 \mathrm{~cm}(H)$ is $15 \%$. The model uses the dependence of plant residues entering the soil on yield. The dependence of yield on humus reserves in the soil (with a decrease in humus reserves yield decreases) was used as well. Therefore, in the first approximation, the value $H$ can be taken as an indicator of soil quality (from the standpoint of yield). Thus, the change in measured values $A, D$ and $H$ determines the soil resources dynamics (their quantity and quality).

\footnotetext{
"Corresponding soil-er@ kursknet.ru
} 


\subsection{The problem of estimating the expected crop yield.}

Yield is a random variable because it depends on deterministic and random factors. The yield trend (in this case, the change of average yield in time) is interpreted as dependence on deterministic factors. Deviations from the trend are interpreted as dependence on random factors. For example, technology refers to deterministic factors, and meteorological conditions to random factors. These factors determine the risk (probability) of producing yields less than the desired value. Field experiments are conducted to investigate the effects of different factors on yield. In fact, these are tests of new technologies. The duration of the experiments is different, and the result is represented, for example, by average yield and economic indicators $[5,6]$; yields, product quality and changes in soil properties [7]; estimated yield - yield trend and risk (probability) of obtaining yield less than the specified value [8].

Long-term field experiments are needed to estimate the expected yield. The results of the experiments for each variant tested are represented by a number of yield values per year, i.e. random sample.

$$
\left\{Y_{i}\right\}, i=1,2, \ldots n
$$

where $Y_{i}$ is the yield for the $i$-th year; $n$ is the number of observation years (sample size).

Using sample (1), the average yield value $Y_{a v}$ is calculated. To evaluate the reliability of this value, one still needs to add the absolute error $\Delta Y_{a v}$ with which it is obtained. Error of $\Delta Y_{a v}$ is determined by the deviation of value $Y_{a v}$ from the value of general population $Y_{g p}$. This error estimates the validity of the average value of $Y_{a v}$, and the error interval $\left(Y_{a v} \pm \Delta Y_{a v}\right)$ represents the result of measuring the average yield. The reliability of the yield difference obtained at the two sites determines the following condition.

$$
\operatorname{abs}\left(Y_{a v, 1}-Y_{a v, 2}\right)>\left(\Delta Y_{a v, 1}+\Delta Y_{a v, 2}\right)
$$

where abs is the function of absolute values; indices 1 and 2 correspond to the first and the second section.

The problem is that the value of $Y_{g p}$ is not known. For this reason, only the average value of $Y_{a v}$ is given. This eliminates the possibility to evaluate the validity of average yield values and the reliability of the yield difference obtained for different technologies. The use of simple methods of mathematical statistics makes it possible to significantly increase the information value of the obtained data on yield [9]. For example, one can estimate the following: error $\Delta Y_{a v}$; yield trend; the risk of obtaining yields less than a given value; probability of expected yield within a given range of values; duration of the experiment to achieve a given error $\Delta Y_{a v}$; reliability of difference of average yields for different technologies. Yields vary greatly by year, so the duration of crop observations is estimated, for example, 10-20 years [9]. During, this time, the technology may become obsolete.

Methods are needed to reduce the duration of field experiments. Such methods can be mathematical modeling methods. Erosion processes reduce soil resources (reduce arable land area, humus layer thickness and humus reserves). This leads to a decrease in the number of products produced. To assess the expected quality of crop products, it is necessary to obtain not only data on yield (1), but also similar data for the quality of the product (the content of useful and harmful substances in it).

\subsection{The problem of assessing the long-term impact of technology on soil resources.}

Various field experiments, such as [10-12], are conducted to investigate these effects.

\subsubsection{The problem of assessing changes in soil properties.}

To reduce the costs of field experiments, they are often carried out on plots with a small area $(A)$. The first case: soil property index has one value. For example, soil density, content of different substances in the soil. The change of indicator values over time determines the dynamics of soil resources. Measurement of $X$ is carried out at different points of the site. As a result, a random sample of values is obtained.

$$
\left\{X_{i}\right\}, i=1,2, \ldots n \text {, }
$$

where $X_{i}$ is the measured value at the $i$-th point of the section; $n$ is the number of measurements (sample volume).

Using sample (3), the mean for the area of the site is calculated as $X_{a v}$. For sample (3), there is a problem of estimating absolute error $\Delta X_{a v}$ for the average value $X_{a v}$. In order to assess the validity of average values of soil indicators and the validity of their change over time, it is necessary to find a solution to this problem, similar to the solution for yield [9]. To assess the long-term effects, samples (3) over the long-term observation period should be obtained. Methods are also needed to analyze this kind of measurement data. It is unrealistic to make measurements for all indicators of soil properties. It is necessary to choose the main ones that more characterize the soil resources used for the production of crop products. The transition to organic farming requires monitoring of soil and crop contaminants. The second case: an indicator of the property of the soil is dependence. For example, when rain falls, the absorption capacity of the soil is determined by time dependence. To assess the change in soil absorption capacity over a long period, you need to switch from dependence to an integral indicator, which is estimated by one number. I.e. you need to get a random sample of values similar to (3), then analyze it. The second case also includes the structural-aggregate composition of the soil. All indicators of soil properties can be conditionally divided into two groups. The first group: the values of the indicators significantly change during the spring-summer-autumn period, for example, the density and humidity of the soil of the treated layer. The second group: the change in indicators can be reliably measured after 10 years or more, for example, the content of humus. The technology may become obsolete during this time. Methods are needed for the application of which the duration of field experiments can be much shorter. Such methods can be mathematical modeling methods. 


\subsubsection{The problem of assessing the long-term effects of erosion processes.}

The main global threats to the soil include erosion [1]. This threat exists for the soils of Russia. According to 1995 data, in Kursk Region (Russia) eroded soils occupied $22.6 \%$ of the arable land area [3]. Soil losses are associated with rain erosion and snowmelt erosion. In subsequent years, the mandatory survey of soils of agricultural land in Russia was discontinued. It can be argued that soil erosion continued, and soil resources decreased. Table 1 presents data for chernozem soils of Kursk Region.

Table1. Chernozem soils of Kursk Region [4].

\begin{tabular}{|l|c|c|c|c|}
\hline \multirow{2}{*}{ Parameter } & \multirow{2}{*}{ Uneroded } & \multicolumn{3}{|c|}{ Erosion Degree } \\
\cline { 3 - 5 } & & Slight & Average & Severe \\
\hline $\begin{array}{l}\text { Humus layer } \\
\text { for the period } \\
\text { of observations } \\
1970 \text {-1980, cm }\end{array}$ & 74 & 55 & 35 & 24 \\
\hline $\begin{array}{l}\text { Average rate of } \\
\text { humus layer } \\
\text { reduction over } \\
\text { 200 years *, } \\
\text { mm/year }\end{array}$ & 0 & 1.0 & 2.0 & 2.5 \\
\hline $\begin{array}{l}\text { Duration of } \\
\text { humus layer } \\
\text { recovery for }\end{array}$ & 0 & 5.6 & 7.8 & 8.7 \\
$\begin{array}{l}\text { VIRGIN SOIL } \\
\text { scenario, } \\
\text { thousand years }\end{array}$ & & & & \\
\hline
\end{tabular}

* - for 200 years after the plowing of virgin soil (approximately for 1780-1980 years)

Using the integrated model [4], a forecast of the dynamics of humus layer depth $(D)$ and humus $(H)$ reserves was developed. The forecast was developed for three scenarios of modern land use and for the VIRGIN SOIL scenario, which determines the transfer of arable land to the deposit with a further transition to virgin soil. The results obtained led to the conclusion that for eroded soils, only the VIRGIN SOIL scenario can provide a restoration of the depth of the humus layer. Table 1 shows that recovery will take 5.6 to 8.7 thousand years. Calculations showed that for modern land use scenarios, the rate of soil formation is $10-100$ times less than the average rate of reduction of the humus layer over 200 years (Table 1). Thus, erosion soil loss is almost impossible to restore. This is consistent with the FAO conclusion [1] that a human uses erodible soil resources as non-reproducible resources. Consequently, in protecting soils from erosion from all indicators of soil properties, the main indicator is the depth of the humus layer $(D)$.

Forecasts have shown that it is almost impossible to stop erosion in a short time. A strategy is needed to manage the remaining soil resources subject to erosion. At each subsequent stage, strategies should reduce allowable erosion soil loss. These losses depend on economic opportunities.

\subsubsection{Problems of large-scale experiments with the use of anti-erosion measures.}

The field experiment CRA (Contour-Reclamation Agriculture), which is conducted by Kursk Federal Agricultural Research Center is taken as an example to consider these problems. The experiment is located in Kursk Region on three catchments with a total area of 146 hectares (the soil is chernozems). No anti-erosion measures (control) were used on one catchment. Different versions of anti-erosion measures were used on the other two. The maximum length of the slopes is $1100 \mathrm{~m}$. The experiment has been conducted for 39 years since 1982 . Problem 1. At the beginning of the experiment, funding was insufficient for detailed measurements of soil properties on the area of all catchments. This has now excluded the possibility of assessing the change in these figures over 39 years in all the catchments. Over time, this was not possible, since funding was reduced. This problem also applies to yields. To assess erosion soil losses during spring snowmelt, measurements were made of the volumes of channels formed by water flows. Soil loss was not measured for rain erosion. This eliminates the possibility of linking the change in soil properties (and yields) with its erosion losses. Problem 2: What are the consequences and how can they be reliably assessed? There is no solution to this problem yet, but we can suggest the following. On each of the two catchments (control and with anti-erosion measures), a slope is distinguished. For the slope after plowing of virgin soil before the start of the experiment (1982), reconstruct the distribution along the slope of the depth of the humus layer $(D)$ and the reserves of humus $(H)$. You can use the integrated model [4] to do this.

As an example, in Fig. 1 shows the profiles of two slopes.

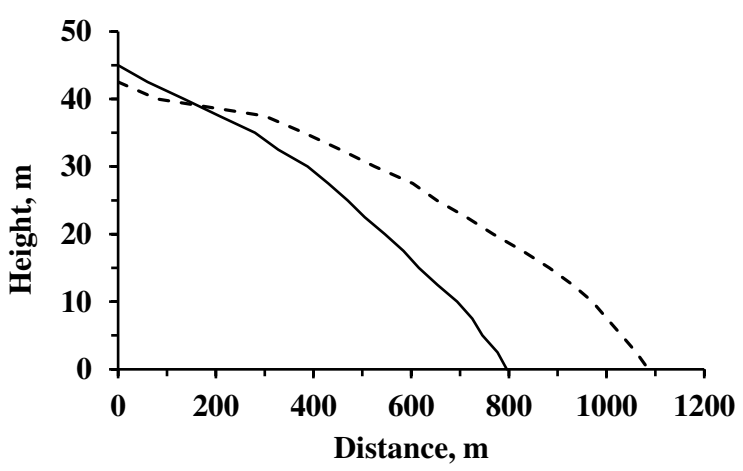

Fig. 1 Profiles of two slopes: solid line - control slope (without anti-erosion measures); dotted line - slope with erosion control measures.

This figure shows that the profiles are different.

Further, on the slope with anti-erosion measures, select the key areas of greatest interest for assessing the effects of soil erosion. For each such site on the slope of another catchment (without erosion measures), choose a similar site. For these two sites on different slopes, erosive soil loss must be the same prior to the experiment.

Figure 2 shows the placement of similar sites on different slopes. 


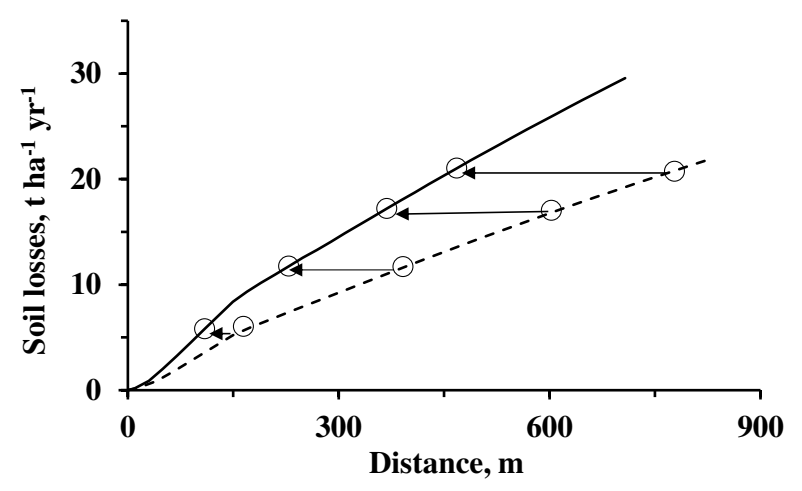

Fig. 2. Distribution of soil erosional losses along the slope and placement of similar areas: solid line - control slope; dotted line - slope with anti-erosion measures: $\bigcirc$ - location of sites on slopes; arrows show similar areas with the same soil loss

After 39 years, in these areas, the difference in the measured values of the soil property indicator will show the effectiveness of anti-erosion measures. All measurements should be carried out in key plots with a small area $(A)$. A random sample of measured values (3) should be obtained at each site for the investigated soil property indicator, and the average $X_{a v}$ value for the area should be calculated. Further, for this value, it is necessary to estimate its absolute error $\Delta X_{a v}$. The measurement result is represented by the error interval $\left(X_{a v} \pm \Delta X_{a v}\right)$. By comparing error intervals for all the key sites, the effectiveness of anti-erosion measures at 39 years versus the control variant can be estimated. This applies to yields as well. Such field experiments are very valuable.

Firstly, they are very rare (they are carried out for different soil and climatic conditions).

Secondly, it will take another 39 years to repeat them with a better methodology.

\subsection{The problem of environmental pollution} assessment.

The main threats to the soil include its global pollution [2]. The main sources of pollution are industry, vehicles, mineral fertilizers applied into the soil (containing pollutants, for example, heavy metals [13]), as well as plant protection aids used. During accidents at nuclear power plants, radioactive substances can get into the soil. As a result, the soil becomes a source of pollution. Air pollution occurs as a result of wind erosion of the soil. Pollutants dissolved in the soil, along with water, fall into groundwater. With surface water runoff, soil pollutants enter surface water bodies. For example, in river water there is an increase in the concentration of nutrients coming from agricultural land [14]. To predict the entry of pollutants from agricultural lands into reservoirs and rivers, complex mathematical models are being developed, for example [15]. To apply such models to innovative technologies in crop production, experimental data on soil pollutant losses are needed. This requires special methods of conducting experimental studies, in particular, using sprinklers [16].

\section{Conclusion.}

Innovative technologies must simultaneously solve three problems: the first is the production of the necessary quantity and quality of crop products (1), the conservation of soil resources (2), and the preservation of the environment (3). To develop new technologies, field experiments are carried out, usually focused on crop yields. There are significantly fewer experiments focused on the effects of soil and environmental technologies. To solve these three problems, there are no necessary methods for solving special problems. As a consequence, there is often no assessment of their validity for the results. Long-term field testing of these technologies is needed to assess the long-term impact of innovative technologies. During this time, technology may become obsolete.

Assessment of the long-term effects of innovative technologies in crop production requires methods of assessing these effects, mathematical and physical modelling methods in particular.

The work was carried out within the framework of the Statetasks of FSBSI«Federal Agricultural Kursk Research Center» on topic No.0632-2019-0017.

\section{References}

1. Status of the World's Soil Resources (SWSR) (Rome, FAO, 2015)

2. N. Rodriguez-Eugenio, M. McLaughlin, D. Pennock, Soil Pollution: a hidden reality (Rome, FAO, 2018)

3. L.F. Litvin, Geography of soil erosion of agricultural lands of Russia 255 (Moscow, Academkniga, 2002)

4. Yu.P. Sukhanovskii, A.V. Prushchik, S.I. Sanzharova, Yu.A. Solov'eva, Zemled. 2, 29-32 (2016)

5. S.D. Gilev, Uu.V. Surkova, Kormoproiz. 7, 20-24 (2018)

6. N.A. Maksyutov, N.A. Zenkova, A.A. Zorov, S.N. Yakovlev, Zhivotnov. i kormoproiz. 101 (1), 190196 (2018)

7. A. Wozniak, Int. J. Plant Prod. 13 (3), 177-182 (2019)

8. D.C. Nielsen, M.F. Vigil, Agron. J. 110 (2) 594-601 (2018)

9. Yu.P. Sukhanovskii, A.S. Akimenko, T.A. Dudkina, A.V. Prushchik, Mezdnar. S.-kh. J. 63 (6), 94-97 (2020)

10. Ph. Götze, J. Rücknagel, A. Jacobs, B. Märländer, O. Christen, Euro. J. of Agron. 76, 198-207 (2016).

11. K.Sh. Kazeev, G.V. Mokrikov, Yu.V. Akimenko, M.A. Myasnikova, S.I. Kolesnikov, Dostiz. nauki i techniki APK 34 (1), 7-11 (2020)

12. M. Dachraoui, A. Sombrero, Soil \& Tillage Research 196, 104472 (2020)

13. N.I. Sanzharova, P.N. Tsygvintsev, V.S. Anisimov, S.A. Geras'kin, V.K. Kuznetsov, N.N. Loy, E.P. Pimenov, P.V. Panov, A.N. Ratnikov, A.I. Sanzharov, L.I. Goncharova, D.G. Sviridenko, S.P. Arysheva, L.N. Anisimova, A.V. Dikarev, G.I. Popova, T.V. Perevolotskaya, A.A. Suslov, L.M. Frigidova, D.V. Vasilyev, D.N. Kurbakov, S.I. Spiridonov, Heavy metals in agrocenoses: migration, 
effect, regulation (Obninsk, FGBNU VNIIRAE, 2019)

14. S.V. Dolgov, N.I. Koronkevich, Izvest. Ros. Akad. Nauk. Ser. Geogr. 5 43-55 (2019)

15. S.A. Kondratyev, M.V. Shumakova Mathematical modeling of mass area-watercourse-water body (St.Petersburg, Nestor-Historia, 2020)

16. A.N. Saber, P. Somjunyakul, J. Ok, H. Watanabe, Water Air Soil Pollut. 226 230-245 (2019) 